\title{
A novel approach for the construction of a Campylobacter mutant library
}

\author{
Nancy M. C. Bleumink-Pluym, Froukje Verschoor, Wim Gaastra, \\ Bernard A. M. van der Zeijst $†$ and Ben N. Fry $\ddagger$
}

\begin{abstract}
Author for correspondence: Nancy M. C. Bleumink-Pluym. Tel: +3130 2534987. Fax: + 31302540784 e-mail: n.bleumink (âjvet.uu.nl
\end{abstract}

Department of Bacteriology, Institute of Infectious Diseases and Immunology, Faculty of Veterinary Medicine, Utrecht

University, Yalelaan 1, 3584

$\mathrm{CL}$ Utrecht, The Netherlands
Given the lack of functional transposons for use in Campylobacter spp., an alternative method of insertional mutagenesis using natural transformation was developed. High efficiencies of transformation were only obtained with species-specific DNA. This feature was a key element in the construction of mutant libraries of this bacterium. A chromosomal library of Campylobacter jejuni 81116 DNA was made in shuttle vector pUOA18. Next, a kanamycinresistance $\left(\mathrm{Km}^{\mathrm{R}}\right)$ cassette was ligated into the inserts of the plasmids. $C$. jejuni 81116 was then transformed with the resulting products to allow homologous recombination between genomic fragments present in the shuttle vector and the chromosome. Transformants were pooled and chromosomal DNA from these transformants was used to retransform $C$. jejuni 81116. This resulted in transformants containing the $\mathrm{Km}^{\mathrm{R}}$ cassette in the chromosome but lacking the vector. In order to evaluate this approach for the construction of a mutant bank, the $\mathrm{Km}^{\mathrm{R}}$ insertional mutants were screened for loss of motility. Partial characterization of 11 non-motile mutants indicated that the inserted genes are involved in motility. Four mutants had the $\mathrm{Km}^{\mathrm{R}}$ cassette inserted in genes involved in flagella biosynthesis, namely flaA/B, neuB and figK, and produced incomplete or no flagella. Four mutants had the $\mathrm{Km}^{R}$ cassette inserted in genes possibly involved in flagella motor function: pflA, fliM and orf1 downstream of the flin gene. Three mutants had the $\mathrm{Km}^{R}$ cassette inserted in genes that are homologous to genes encoding hypothetical proteins of Helicobacter pylori.

Keywords: Campylobacter jejuni, mutant library, motility mutants, genetics

\section{INTRODUCTION}

Campylobacter jejuni is a Gram-negative bacterium which is widespread in nature. It is one of the major causes of human enteritis both in developed and developing countries (Tauxe, 1992; Taylor, 1992), but it is also a commensal of many animal species (Skirrow \& Blaser, 1992). How C. jejuni causes disease is only partially known. So far, the flagella have been proven to play an important role in pathogenicity (Grant et al., 1993; Ruiz-Palacios et al., 1992; Wassenaar et al., 1991; Yao et al., 1994). The identification and characterization of C. jejuni virulence factors have been hampered by the

\footnotetext{
tPresent address: National Institute of Public Health and the Environment, Vaccine Division, PO Box 1, 3720 Bilthoven, The Netherlands.

ҒPresent address: Department of Applied Biology and Biotechnology, Royal Melbourne Institute of Technology University, 124 LaTrobe Street, Melbourne, VIC 3000, Australia.
}

lack of an animal model and the sparsity of useful genetic tools. Given the lack of functional transposons for use in Campylobacter spp., alternative methods to obtain mutants are needed.

Some strains of C. jejuni are naturally transformable (Wassenaar et al., 1993). This has been shown to be the most efficient way for DNA uptake in C. jejuni strain 81116 (Wassenaar et al., 1993). Methods for insertional mutagenesis have been described for several bacteria which, like Campylobacter spp., are naturally transformable (Labarre et al., 1989; Sharetzsky et al., 1991). Also for Campylobacter spp. several attempts have been made to construct a mutant library; Yao et al. (1994) used an adaptation of a method described originally by Sharetzsky et al. (1991) for Haemophilus influenzae, while Dickinson et al. (1995) have used integrational plasmid vectors. However, complete libraries could not be constructed, mainly due to low frequencies of transformation. 
With the knowledge obtained on natural transformation of C. jejuni 81116 we have developed a novel approach for the construction of a mutant library of this bacterium. This new approach is an alternative for transposon mutagenesis. To evaluate the mutagenesis procedure the mutants were screened for non-motility, which is an easily detectable phenotype. We have isolated and partially characterized non-motile mutants from this library.

\section{METHODS}

Bacterial strains and plasmids. The origin of C. jejuni strain 81116, its Fla" phase variant and its flagellin mutant R1 $\left(f l a A:: \mathrm{Km}^{\mathrm{R}}\right.$ ) have been described previously (Wassenaar et al., 1991). Escherichia coli strain DH5 (Sambrook et al., 1989) was used as a host for plasmid pUOA18 in the experiments for optimizing natural transformation.

The shuttle vector pUOA18 containing the chloramphenicolresistance gene has been described previously (Wang \& Taylor, 1990). pILL550 (Labigne-Roussel et al., 1987) was the original source of the kanamycin-resistance $\left(\mathrm{Km}^{\mathrm{R}}\right)$ cassette. pBF14 is a pUOA18 vector containing the $\mathrm{Km}^{\mathrm{R}}$ cassette flanked by two polylinkers and used to obtain $\mathrm{Km}^{\mathrm{R}}$ cassettes with BamHI, PstI or PvuII (blunt) ends. pBF6 is a pBluescript vector containing the $f l a A$ and $f l a B$ genes of $C$. jejuni 81116 separated by a $\mathrm{Km}^{\mathrm{R}}$ cassette. pBF10 is the pUOA18 vector containing the insert from pBF6.

Media and growth conditions. C. jejuni strain 81116 was grown under microaerophilic conditions on Skirrow agar medium (Skirrow, 1977) at $42^{\circ} \mathrm{C}$ for $48 \mathrm{~h}$. E. coli was grown in $\mathrm{LB}$ medium at $37^{\circ} \mathrm{C}$. Antibiotic concentrations used were as follows: chloramphenicol (Sigma), $20 \mu \mathrm{g} \mathrm{ml}^{-1}$; kanamycin (Sigma), $30 \mu \mathrm{g} \mathrm{ml}^{-1}$; ampicillin (Centrafarm), $100 \mu \mathrm{g} \mathrm{m}^{-1}$. For motility tests bacteria were grown in thioglycollate medium (BBL) containing 0.4\% agar (Caldwell et al., 1985). The human embryonic intestine cell line (INT407) was obtained from Flow Laboratories and maintained in Dulbecco's modified Eagle's medium (DMEM; Gibco) supplemented with $5 \%$ heat-inactivated foetal calf serum (Gibco), penicillin (Gibco; $100 \mathrm{U} \mathrm{ml}^{-1}$ ) and streptomycin (Gibco; $10 \mu \mathrm{g} \mathrm{m}^{-1}$ ).

Recombinant DNA techniques. DNA isolation, restriction enzyme digestion and DNA ligation were performed as described by Ausubel et al. (1992). Restriction enzymes were obtained from Pharmacia Biotech Benelux. DNA fragments for subcloning and for use as probes were isolated from agarose gels using the GenecleanII kit (Bio101). The flaA gene of C. jejuni 81116 was amplified by PCR using primers CGTATTAACACAAATGTTGCAGCA and CTGCTGCTTTAACATTAACTTGAG (nucleotides 92-115 and 16531675 of database entry J05635) and used as probe. Probes for hybridization experiments were labelled with digoxigenindUTP using the DIG DNA labelling kit (Boehringer Mannheim). Hybridizations were performed at $62{ }^{\circ} \mathrm{C}$ and the DIGlabelled nucleic acid hybrids were detected using the DIG Luminescent Detection kit (Boehringer Mannheim). Plasmid DNA used for sequencing reactions was purified by using the Qiagen plasmid kit.

Natural transformation. For natural transformation of $C$. jejuni 81116 with plasmid or chromosomal DNA the bacteria were cultured overnight and harvested in heart infusion $(\mathrm{HI}$; Difco) broth and diluted to a concentration of $10^{8}$ c.f.u. $\mathrm{ml}^{-1}$. To induce competence, $200 \mu \mathrm{l}$ cells was incubated for $3 \mathrm{~h}$ at
$37{ }^{\circ} \mathrm{C}$ under microaerophilic conditions on $1 \mathrm{ml} \mathrm{HI}$ agar in a $2.0 \mathrm{ml}$ micro test tube (Eppendorf), hereby creating a biphasic medium. Then, DNA was added and incubated for $3 \mathrm{~h}$ at $37^{\circ} \mathrm{C}$ under microaerophilic conditions. Cells were harvested and plated on Skirrow plates supplemented with the appropriate antibiotics and incubated for $48 \mathrm{~h}$ at $42{ }^{\circ} \mathrm{C}$.

Construction of the mutant library. Firstly, a genomic library of C. jejuni 81116 was made by partial digestion of chromosomal DNA with Sau3AI. After fractionation by centrifugation in $10-40 \%$ sucrose gradients, fragments of $0.5-5 \mathrm{~kb}$ were isolated. To prevent self-ligation the sticky ends of $10 \mu \mathrm{g}$ DNA were partially filled in with $1 \mu 130 \mathrm{mM}$ dATP and dGTP and $3 \mathrm{U}$ Klenow fragment in a volume of $100 \mu \mathrm{l}$ for $15 \mathrm{~min}$ at $37^{\circ} \mathrm{C}$. The vector pUOA 18 , isolated from C. jejuni 81116 , was digested with Sall and partially filled in with dCTP and dTTP as described above. After extraction with phenol/chloroform and ethanol precipitation, fragments and vector were ligated with T4 DNA ligase for $48 \mathrm{~h}$ at $16^{\circ} \mathrm{C}$. The ligation mixture was used to transform C. jejuni 81116 wild-type cells by natural transformation and plated onto Skirrow plates with chloramphenicol. The resulting library contained 15000 transformants.

Secondly, plasmid DNA was isolated from this pool of transformants and $10 \mu \mathrm{g}$ was digested with $B g l \mathrm{II}, B c l \mathrm{I}, B s t \mathrm{EII}$, $N$ sil or EcoRV. The $\mathrm{Km}^{\mathrm{R}}$ cassette, also isolated from C. jejuni 81116 , was ligated into these restriction sites in a volume of $20 \mu \mathrm{l}$ for $48 \mathrm{~h}$ at $16^{\circ} \mathrm{C}$. The BglII, BclI, Bst EII, Nsil or EcoRV sites were not restored by using $\mathrm{Km}^{\mathrm{R}}$ cassettes with $B a m \mathrm{HI}$, PstI or PvuII ends. These ligation mixtures were used to transform C. jejuni 81116 wild-type cells and resulted in five different batches of $>1000$ transformants.

Finally, chromosomal DNA was isolated from the batches of pooled transformants and used to transform the wild-type strain 81116 by a second round of natural transformation. The resulting transformants were grown on Skirrow plates with kanamycin and Skirrow plates with chloramphenicol to confirm the presence of the $\mathrm{Km}^{\mathrm{R}}$ cassette in the chromosome and the absence of the shuttle vector pUOA18.

DNA sequence analysis of the insertional mutants. Circularized $B g l \mathrm{II}-\mathrm{Bcl}$ I, AseI or HinfI chromosomal DNA fragments from the $C$. jejuni non-motile mutants were used as template in the inverse PCR. Two primers reaching outward from within the $\mathrm{Km}^{\mathrm{R}}$ cassette were used to determine the point of insertion of the $\mathrm{Km}^{\mathrm{R}}$ cassette. Primer 1 (TATCACCTCAAATGGTTCGCTGGG) corresponds to nucleotides 36-50 and primer 2 (GGGGATCAAGCCTGATTGGGAGA) contains the nucleotides $1368-1390$ of the $\mathrm{Km}^{\mathrm{R}}$ cassette (nucleotides 7-21 and 1339-1361 of database entry M26832, respectively). Inverse PCR was performed in a Gene Amp 9600 Thermocycler (Perkin-Elmer Cetus). The cycling conditions were as follows: 35 cycles of $15 \mathrm{~s}$ of denaturation at $94^{\circ} \mathrm{C}$; $10 \mathrm{~s}$ of primer annealing at $65^{\circ} \mathrm{C}$; and $2 \mathrm{~min}$ of extension at $72{ }^{\circ} \mathrm{C}$; followed by a final extension of $5 \mathrm{~min}$ at $72{ }^{\circ} \mathrm{C}$. The inverse PCR product was cloned in the pGEM-T Easy vector (Promega). The sequence of the cloned DNA was determined by the dideoxy chain-termination method (Sanger et al., 1977) with an Automated Laser Fluorescent DNA Sequencer (Pharmacia), the autoread sequencing kit using T7 DNA polymerase (Pharmacia) and the fluorescein-labelled nucleotide primers T7 and SP6 (Pharmacia).

The 2.0 version of the BLAST program (Altschul et al., 1990) was used to compare nucleotide sequences with those in 
Table 1. Characterization of $C$. jejuni strain 81116 non-motile mutants

\begin{tabular}{|c|c|c|c|c|c|c|c|}
\hline \multirow[t]{3}{*}{ Mutant } & \multirow{3}{*}{$\begin{array}{c}\text { Site of } \mathrm{Km}^{\mathrm{R}} \\
\text { insertion }\end{array}$} & \multirow[t]{3}{*}{ Flagella } & \multicolumn{5}{|c|}{ Mutated gene } \\
\hline & & & \multirow[t]{2}{*}{ Similarity } & \multicolumn{2}{|c|}{ Percentage identity ${ }^{*}$} & \multirow[t]{2}{*}{ Function or structure } & \multirow[t]{2}{*}{ Database entry } \\
\hline & & & & 1 & 2 & & \\
\hline $\mathrm{BC} ; 1$ & $B g / I I$ & Normal & pflA, C. jejuni & $99 \%$ over 282 bases & $99 \%$ over 423 bases & Flagella movement & CJ109019 \\
\hline $\mathrm{BC} ; 2$ & BglII & None & neuB, C. jejuni & $96 \%$ over 194 bases & $95 \%$ over 150 bases & Sialic acid synthase & A J 0000855 \\
\hline \multirow[t]{2}{*}{$\mathrm{BG} 3$} & $B y / I I$ & None & AlaA, C. jejuni & $100 \%$ over 224 hases & & Flagelin $A$ & jo5t.3.5 \\
\hline & & & flaB, C. coli & & $89 \%$ over 166 bases & Flagellin B & $M 64671$ \\
\hline \multirow[t]{2}{*}{ BG4 } & $B g / I I$ & Normal & Unknown, $H$. pylori & $66 \%$ over 4.3 aa & & $\begin{array}{l}\text { Hypothetical integral } \\
\text { membrane protein }\end{array}$ & AF.000) 12 gene HPI(144 \\
\hline & & & flgK, H. pylori & & $61 \%$ over 80 aa & HAPI & $\mathrm{AE}\left(000618\right.$ gene $\mathrm{HP}^{3} 1119$ \\
\hline $\mathrm{BC} ; 5$ & $B g / l I$ & Normal & Unknown & & & & \\
\hline$B C i 6$ & BglII & Normal & $\mathrm{NP}$ & & & & \\
\hline \multirow[t]{2}{*}{$\mathrm{BC} 7$} & $B c h$ & Stump & flgK, H. pylori & $85 \%$ over 20 aa & & HAP1 & AF:(OOOG 18 gene HPIIIY \\
\hline & & & Unknown, H.pylori & & $52 \%$ over 98 a & Hypothetical protein & AFooos 44 gene HP(0245 \\
\hline BS8 & $B s t \mathrm{EIl}$ & Normal & orf1-fliN, C. jejuni & $98 \%$ over 220 bases & $88 \%$ over 153 bases & Hypothetical protein & $A J(0)(0) 4(K)$ \\
\hline \multirow[t]{2}{*}{ BSY } & BstEll & Normal & orf1-fiN, C. jejuni & $56 \%$ over 61 aa & & Hypothetical protein & A J000400 \\
\hline & & & flic, S. marcescens & & $67 \%$ over 35 a & FlagelJin & P1.3713 \\
\hline NS10 & $N s i l$ & Normal & fiM, H. pylori & $56 \%$ over 24.3 bases & & Flagellar motor switch & AE000611 gene HP1031 \\
\hline EC:11 & $E c o \mathrm{RV}$ & None & Unknown, $H$. pylori & $53 \%$ over 111 aa & & Hypotherical protein & AE 000533 gene HP(0114 \\
\hline
\end{tabular}

NP, Not possible to determine because inverse PCR failed.

* The two columns refer to the sides flanking the kanamycin insertion.

databases available at Genome Net (www.ncbi.nlm.nih.gov/ BLAST/). The database entry codes are given in Table 1 .

Invasion assay. To roughly estimate the invasive capacity of the non-motile mutants we adapted the invasion assay of Wassenaar et al. (1991). Briefly, approximately $10^{7}$ bacteria were added to a confluent monolayer of $10^{5}$ INT407 cells per well in a 24-well plate. After an incubation period of $1 \mathrm{~h}$ at $37{ }^{\circ} \mathrm{C}$ and $5 \% \mathrm{CO}_{2}$, the monolayers were washed five times with DMEM and reincubated for another $3 \mathrm{~h}$ with DMEM containing $250 \mu \mathrm{g}$ gentamicin $\mathrm{ml}^{-1}$. Following this second incubation, the monolayers were washed three times with PBS and lysed in $0.5 \mathrm{ml}$ PBS containing $0.5 \%$ Triton X-100. To determine the number of intracellular bacteria, $50 \mu \mathrm{l}$ of the $10^{-1}$ dilution was plated on Skirrow agar plates. We observed 500 or more colonies when C. jejuni 81116 wild-type was used in this assay, while no colonies were observed with the nonmotile Fla- variant.

Electron microscopy. Bacteria were grown on Skirrow agar plates for $24 \mathrm{~h}$ at $42{ }^{\circ} \mathrm{C}$ and suspended in $2 \%$ bovine serum albumin in PBS. Next, the bacteria were incubated on 200mesh copper grids coated with Formvar, stained in $2 \%$ tungstophosphoric acid $(\mathrm{pH} \mathrm{6.8)}$ for $2 \mathrm{~min}$ and examined in a Philips CM 10 electron microscope.

\section{RESULTS}

\section{Optimizing the efficiency of natural transformation}

Three different suicide and shuttle vector constructs have been used to optimize natural transformation of $C$. jejuni strain 81116. No transformants were obtained when the shuttle vector pUOA18 originating from either C. jejuni strain 81116 or E. coli was used. C. jejuni could be transformed with the suicide vector pBluescript containing the flaA and flaB genes of C. jejuni 81116 originating from $E$. coli if at least $10 \mu \mathrm{g}$ DNA was used. However, the cloning of the same flaA and flaB genes in the pUOA18 shuttle vector resulted in 80 transformants ( $\mu \mathrm{g}$ DNA $)^{-1}$ when the plasmid was isolated from E. coli, (a)

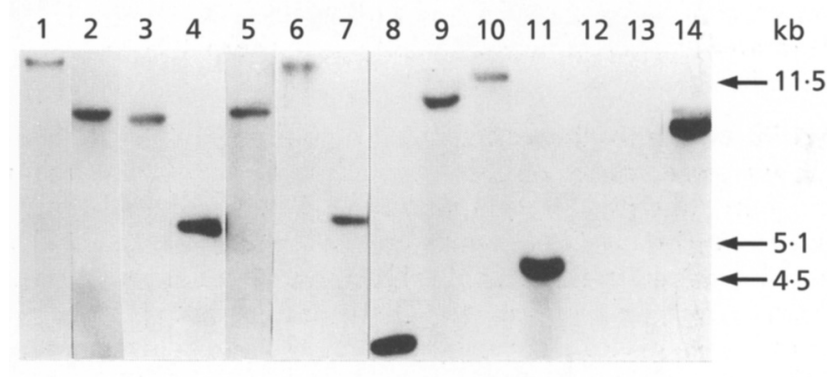

(b)

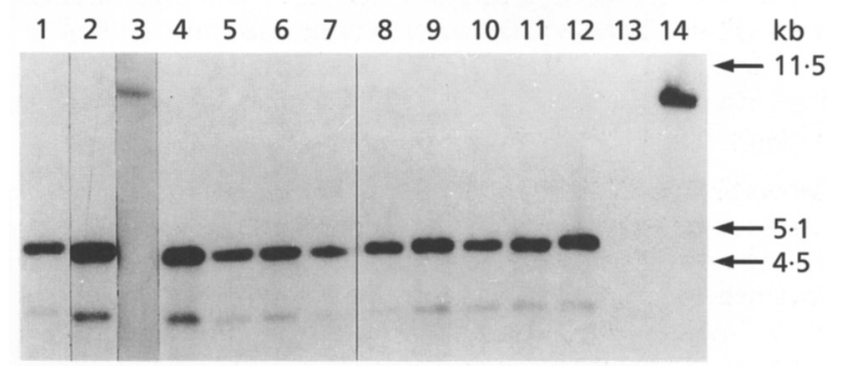

Fig. 1. Southern blot analysis of DNAs from non-motile mutants of C. jejuni 81116 digested with $B g / l l$ and probed with the $\mathrm{Km}^{\mathrm{R}}$ cassette (a) and the flaA gene (b). Lanes: $1, B G 1 ; 2, B G 2 ; 3$, BG3; 4, BG4; 5, BG5; 6, BG6; 7, BC7; 8, BS8; 9, BS9; 10, NS10; 11, EC11; 12, wild-type; 13 , pUOA 18; 14, R1. Molecular size markers are indicated on the right.

and $1.6 \times 10^{5}$ transformants when isolated from C. jejuni strain 81116 . These results confirm the high speciesspecificity for DNA in natural transformation of strain 81116. To obtain a high transformation efficiency of $C$. jejuni strain 81116, in subsequent experiments plasmid DNA was always isolated from C. jejuni strain 81116. 

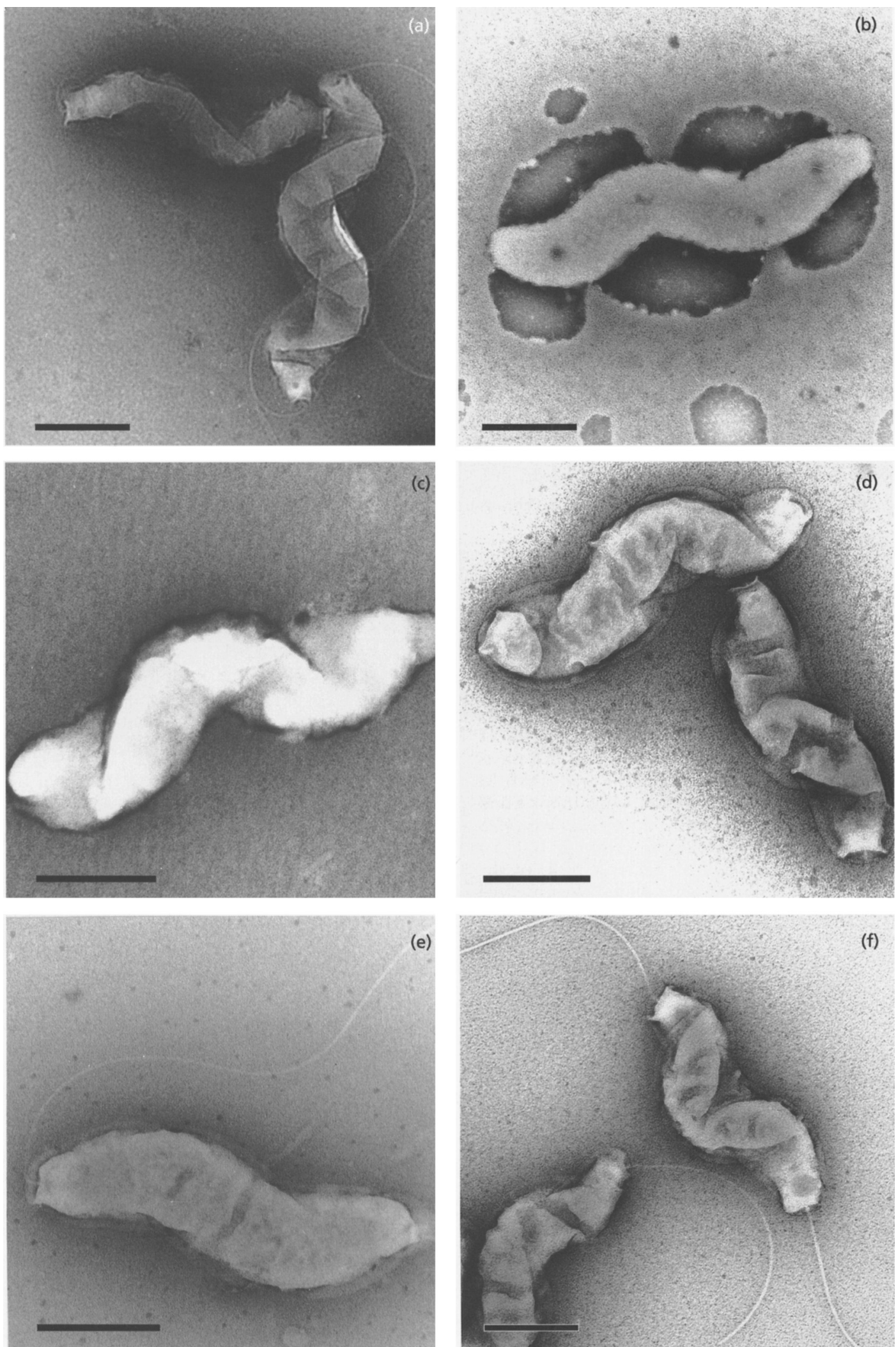

Fig. 2. Electron micrographs of the C. jejuni 81116 wild-type (a) and non-motile mutants BG2 (b), BG3 (c), BC7 (d), BS8 (e) and NS10 (f). Bars, $0.5 \mu \mathrm{m}$. 


\section{Construction and screening of the insertional mutant library}

The mutants were constructed as described in Methods. Briefly, chromosomal DNA of strain 81116 was partially digested with Sau3AI. A chromosomal library was made by ligating the resulting fragments of $0.5-5 \mathrm{~kb}$ in shuttle vector pUOA18, isolated from C. jejuni 81116. Next, a $\mathrm{Km}^{\mathrm{R}}$ cassette, also isolated from C. jejuni 81116, was inserted in several restriction sites present in the inserts of the plasmids from this library. The C. jejuni wild-type strain 81116 was then transformed with this library by natural transformation. The transformants were cultured for $48 \mathrm{~h}$ to enable recombination between the DNA inserts of the shuttle vectors and the chromosomal DNA.

Chromosomal DNA was isolated from the pooled transformants and used to transform the wild-type strain 81116 . This second round of natural transformation was performed to ensure that the resulting $\mathrm{Km}^{\mathrm{R}}$ transformants lacked the shuttle vector and contained the $\mathrm{Km}^{\mathrm{R}}$ cassette in the chromosome.

A total of $1300 \mathrm{Km}^{\mathrm{R}}$ transformants was screened for motility in semi-solid thioglycollate medium. Eleven non-motile mutants were identified and their non-motile phenotype was confirmed microscopically. In order to be certain that the observed phenotype resulted from insertion of the $\mathrm{Km}^{\mathrm{R}}$ cassette and not from a motility phase switch or a secondary mutation, total DNA was extracted from each mutant and used to retransform the wild-type strain 81116 . All resulting $\mathrm{Km}^{\mathrm{R}}$ transformants were non-motile, showing that the acquisition of $\mathrm{Km}^{\mathrm{R}}$ correlated with acquisition of the non-motile phenotype. All mutants were susceptible to chloramphenicol, indicating the absence of the pUOA18 shuttle vector.

\section{Characterization of the non-motile mutants}

The mutants showing motility defects (listed in Table 1) were chosen to study the molecular events associated with the mutagenesis procedure. Chromosomal DNA from these mutants was analysed in a Southern blot and probed with the $\mathrm{Km}^{\mathrm{R}}$ cassette (Fig. 1a). Since a complete library should contain at least a mutant with a $\mathrm{Km}^{\mathrm{R}}$ cassette in one of the flagella genes $(f l a A$ or $f l a B)$, all mutants were also hybridized to a flaA probe (Fig. 1b). One mutant (BG3) showed a hybridization pattern similar to the flagellin A mutant R1 (flaA:: $\mathrm{Km}^{\mathrm{R}}$ ) (Wassenaar et al., 1991), indicating the presence of a $\mathrm{Km}^{\mathrm{R}}$ cassette in the BglII site of the flaA gene (Fig. $1 \mathrm{~b}$, lanes 3 and 14). By sequencing the flanking regions of the $\mathrm{Km}^{\mathrm{R}}$ cassette, we could demonstrate that a $3.4 \mathrm{~kb}$ BgllI fragment containing a part of the $f l a A$ gene and the complete $f l a B$ gene was deleted.

To determine the morphology of the mutants, they were examined by electron microscopy. One mutant had truncated flagella (BC7), three mutants completely lacked flagella (BG2, BG3 and EC11) and seven mutants had flagellar filaments with the same length as the wildtype strain (Fig. 2).
When tested in an invasion assay, all 11 mutants showed a more than 100 -fold reduction of invasiveness, compared to the wild-type strain (results not shown).

\section{DNA sequence analysis of the non-motile insertional mutants}

The flanking regions of the $\mathrm{Km}^{\mathrm{R}}$ cassette were amplified by inverse PCR on circularized genomic BglII-Bcll, AseI or Hinfl fragments. The resulting PCR products were cloned in the pGEM-T Easy vector and their sequences were determined. A search in the databases available at Genome Net (www.ncbi.nlm.nih.gov/BLAST/) indicated the position of the $\mathrm{Km}^{\mathrm{R}}$ insertion. The position of the $\mathrm{Km}^{\mathrm{R}}$ insertions in the non-motile mutants and their phenotypes are summarized in Table $1 . \mathrm{A} \mathrm{Km}^{\mathrm{R}}$ insertion was found in the $p f l A$ gene (Yao et al., 1994) for mutant BG1 and the neuB gene (A. Karlyshev, database entry A J000855) for mutant BG2. The $\mathrm{Km}^{\mathrm{R}}$ insertion in mutant BG3 was flanked on one side by the flaA gene (Nuijten et al., 1990) while the other side was located downstream of the flaB gene (Guerry et al., 1991). In mutant BS8 the $\mathrm{Km}^{\mathrm{R}}$ cassette was inserted in a gene that showed homology with the orf1 located downstream of the fliN gene of C. jejuni (A. Karlyshev, database entry A J000400). The $\mathrm{Km}^{\mathrm{R}}$ cassette in mutant BS9 was flanked by the orf 1 located downstream of the fliN gene and sequences which corresponded at the amino acid level with the $\mathrm{fliC}$ gene of Serratia marcescens (Harshey et al., 1989). In mutant NS10 we have identified one flanking region which was homologous to the fliM gene of Helicobacter pylori (Tomb et al., 1997).

The flanking regions of the $\mathrm{Km}^{\mathrm{R}}$ insertions in mutants BG4, BC7 and EC11 were only at the amino acid level homologous with genes of $H$. pylori. In mutants BG4 and $\mathrm{BC7}$ one flanking region showed homology to the flagellar hook-associated protein (HAP1; Tomb et al., 1997) while the other flanking regions were homologous to genes encoding different hypothetical proteins. The flanking regions of the $\mathrm{Km}^{\mathrm{R}}$ cassette in mutant EC11 corresponded also at the amino acid level with a gene encoding a hypothetical protein of $H$. pylori (Tomb et al., 1997).

The flanking regions of the $\mathrm{Km}^{\mathrm{R}}$ cassette in mutant BG5 showed no homology with known genes. We were unable to determine the sequence of the flanking regions of the $\mathrm{Km}^{\mathrm{R}}$ cassette in mutant BG6.

\section{DISCUSSION}

We describe here a novel approach for the construction of mutant libraries of C. jejuni strain 81116 using natural transformation. In C. jejuni DNA uptake by means of natural transformation is highly efficient when DNA sequences identical to the incoming DNA are already present in the acceptor cell (Wang \& Taylor, 1990; Wassenaar et al., 1993). Additionally, the use of DNA isolated from the same bacterial strain as the acceptor cell, thus carrying the same restriction modifications, greatly enhances the efficiency of transform- 
ation. These two features are key elements in the construction of the mutant library described here. Furthermore, recombinations between the incoming plasmids and the chromosome were facilitated by the use of a multi-copy shuttle vector. To our knowledge this is the first report on recombinations occurring between a shuttle vector and chromosomal DNA. When given enough time by using a shuttle vector as opposed to a suicide vector the frequency of crossover events is high in C. jejuni.

The positions of the $\mathrm{Km}^{\mathrm{R}}$ cassette within the inserts of the mutant library are not random. They are based on the presence of $B g l \mathrm{II}, B c l \mathrm{l}, B s t \mathrm{EII}, N s i \mathrm{I}$ or EcoRV restriction sites in the inserts of the chromosomal library. These restriction enzymes were selected since their sites are absent in the pUOA 18 vector. The position of the restriction site in the inserts determines the length of homologous DNA flanking the $\mathrm{Km}^{\mathrm{R}}$ cassette and thus the efficiency of the homologous recombination. A stretch of $200 \mathrm{bp}$ of homologous DNA is sufficient for recombinational events, but the frequency of recombination increases with longer homologous stretches (Wassenaar et al., 1993). If homologous sequences of sufficient length are present on both sides of the $\mathrm{Km}^{\mathrm{R}}$ cassette a double-crossover event will take place, resulting in the insertion of the $\mathrm{Km}^{\mathrm{R}}$ cassette into the chromosome.

If two or more restriction sites of the same enzyme are present in the insert, a deletion of a particular fragment can be followed by an insertion of the $\mathrm{Km}^{\mathrm{R}}$ cassette. In mutant BG1 a BgllI fragment of $513 \mathrm{bp}$ from the $p f l A$ gene was replaced by the $\mathrm{Km}^{\mathrm{R}}$ cassette. In mutant BG3 a $3.4 \mathrm{~kb} \mathrm{BglII}$ fragment containing the $3^{\prime}$ part of the fla $\mathrm{A}$ gene and the complete flaB gene was replaced by the $\mathrm{Km}^{\mathrm{R}}$ cassette.

The mutants were tested for motility and partially characterized in order to evaluate the mutagenesis procedure. The characterization of the non-motile mutants supports the concept that the inserted genes are involved in motility.

Insertions were detected in three genes involved in flagella formation: $f l a A / B$, neuB and $\lg K$. An insertion of the $\mathrm{Km}^{\mathrm{R}}$ cassette in the major flagellin subunit genes, fla $A$ and $f l a B$, prevented the synthesis of flagellin $A$ and flagellin $\mathrm{B}$, and consequently the formation of flagella, thus explaining the non-motile phenotype of mutant BG3. A Km ${ }^{\mathrm{R}}$ insertion was also detected in the neuB gene, encoding a sialic acid synthase. The post-translational modification of Campylobacter flagellin includes sialic acid (Doig et al., 1996), and may explain the $\mathrm{Fla}^{-}$phenotype of mutant BG2. Our data also demonstrate an insertion in the putative $f \lg K$ gene, encoding the HAP1 protein. In Salmonella the HAP1 displaces the hook cap to form the first hook-filament junction zone, followed by distal assembly of the HAP3 protein, HAP2 protein and flagellin subunits (Macnab, 1996). We characterized two different mutants (BG4, BC7) with one region homologous to the $f l g K$ gene of $H$. pylori flanking the $\mathrm{Km}^{\mathrm{K}}$ cassette and one region homologous to different hypothetical proteins of $H$. pylori (Tomb et al., 1997). The genes encoding these different hypothetical proteins must be located within $5 \mathrm{~kb}$ of the putative $f l g K$ gene since this is the maximum size of the inserts in our chromosomal library before introduction of the $\mathrm{Km}^{\mathrm{R}}$ cassette. Mutant BC7 had stump-like flagella, which is in line with the mutated $f \lg K$ gene and the non-motile phenotype. However, mutant BG4 had long flagella. Apparently it still contains a functional HAP1.

Insertions were also detected in three genes possibly involved in the flagellar motor function: $p f l A, f l i M$ and orf1 downstream of fliN. The flagellated mutant BG1 with the $\mathrm{Km}^{\mathrm{R}}$ cassette insertion in the pflA gene has paralysed flagella and was the same as the mutant generated from plasmid RY 302 as described by Yao et al. (1994). An insertion of the $\mathrm{Km}^{\mathrm{R}}$ cassette in the fliM gene or in the orf 1 located downstream of the fliN gene may lead to a switching defect since the FliN protein presumably interacts with the FliG and the FliM protein to form the switch complex in a similar way as described for Salmonella (Toker \& Macnab, 1997).

$\mathrm{Km}^{\mathrm{R}}$ insertions were also found in genes with no homology to known genes. The observed phenotypes of these mutants $\left(\mathrm{Mot}^{-}, \mathrm{Inv}^{-}\right.$and $\left.\mathrm{Fla}^{+/-}\right)$confirm that the genes must be involved in motility. Further characterization will be needed to reveal their function.

In E. coli and Salmonella more than 40 genes, organized in 15 (E. coli) or 17 (Salmonella typhimurium) operons, are involved in flagellar assembly, structure and function (Macnab, 1996). The size of the genome of Campylobacter is only $37 \%$ of that of these two bacteria. If the number of motility genes would be proportionally lower, additional genes involved in the motility of $C$. jejuni remain to be recovered.

So despite the limitation that the mutants are not completely random, the method described here to construct a mutant library in C. jejuni is the best that is presently available. The method may also be applicable for exploring the genetics of Campylobacter spp. and related organisms which are also naturally transformable. The method has potential for improvement. The construction of Campylobacter vectors with fewer restriction sites will enable the creation of more 'random' mutant libraries. Furthermore, by adding unique DNA sequence tags to the $\mathrm{Km}^{\mathrm{R}}$ cassette this system could be used to identify virulence genes involved in colonization and invasion in vivo (Hensel et al., 1995).

\section{ACKNOWLEDGEMENTS}

We thank Ton Ultee from the Department of Pathology for making the electron micrographs.

Altschul, S. F., Gish, W., Miller, W., Myers, W. E. \& Lipman, D. J. (1990). Basic local alignment search tool. J Mol Biol 215, 403-410.

Ausubel, F. M., Brent, R., Kingston, R. E., Moore, D. D., Seidman, J. G., Smith, J. A. \& Struhl K. (editors) (1992). Short Protocols in Molecular Biology, 2nd edn. New York: Wiley. 
Caldwell, M. B., Guerry, P., Lee, E. C., Burans, J. P. \& Walker, R. I. (1985). Reversible expression of flagella in Campylobacter jejuni. Infect Immun 50, 941-943.

Dickinson, J. H., Grant, K. A. \& Park, S. F. (1995). Targeted and random mutagenesis of the Campylobacter coli chromosome with integrational plasmid vectors. Curr Microbiol 31, 92-96.

Doig, P., Kinsella, N., Guerry, P. \& Trust, T. J. (1996). Characterization of a post-translational modification of Campylobacter flagellin: identification of a sero-specific glycosyl moiety. Mol Microbiol 19, 379-387.

Grant, C. C., Konkel, M. E., Cieplak, W., Jr \& Tompkins, L. S. (1993). Role of flagella in adherence, internalization, and translocation of Campylobacter jejuni in nonpolarized and polarized epithelial cell cultures. Infect Immun 61, 1764-1771.

Guerry, P., Alm, R. A., Power, M. E., Logan, S. M. \& Trust, T. J. (1991). Role of two flagellin genes in Campylobacter motility. $J$ Bacteriol 173, 4757-4764.

Harshey, R. M., Estepa, G. \& Yanagi, H. (1989). Cloning and nucleotide sequence of a flagellin-coding gene (hag) from Serratia marcescens 274. Gene 79, 1-8.

Hensel, M., Shea, J. E., Gleeson, C., Jones, M. D., Dalton, E. \& Holden, D. W. (1995). Simultaneous identification of bacterial virulence genes by negative selection. Science 269, 400-403.

Labarre, J., Chauvat, F. \& Thuriaux, P. (1989). Insertional mutagenesis by random cloning of antibiotic resistance genes into the genome of the cyanobacterium Synechocystis strain PCC 6803. J Bacteriol 171, 3449-3457.

Labigne-Roussel, A., Harel, J. \& Tompkins, L. (1987). Gene transfer from Escherichia coli to Campylobacter species: development of shuttle vectors for genetic analysis of Campylobacter jejuni. J Bacteriol 169, 5320-5323.

Macnab, R. M. (1996). Flagella and motility. In Escherichia coli and Salmonella: Cellular and Molecular Biology, pp. 123-145. Edited by F.C. Neidhardt and others. Washington, DC: American Society for Microbiology.

Nuijten, P. J., van Asten, F. J., Gaastra, W. \& van der Zeijst, B. A. M. (1990). Structural and functional analysis of two Campylobacter jejuni flagellin genes. J Biol Chem 265, 17798-17804.

Ruiz-Palacios, G. M., Cervantes, L. E., Newburg, D. S., LopezVidal, Y. \& Calva, J. J. (1992). In vitro models for studying Campylobacter infections. In Campylobacter jejuni: Current Status and Future Trends, pp. 176-183. Edited by I. Nachamkin, M. J. Blaser \& L. S. Tompkins. Washington, DC: American Society for Microbiology.

Sambrook, J., Fritsch, E. F. \& Maniatis, T. (1989). Molecular Cloning: a Laboratory Manual, 2nd edn. Cold Spring Harbor, NY: Cold Spring Harbor Laboratory.
Sanger, F., Nicklen, S. \& Coulson, A. R. (1977). DNA sequencing with chain-terminating inhibitors. Proc Natl Acad Sci USA 74, 5463-5467.

Sharetzsky, C., Edlind, T. D., LiPuma, J. J. \& Stull, T. L. (1991). A novel approach to insertional mutagenesis of Haemophilus influenzae. J Bacteriol 173, 1561-1564.

Skirrow, M. B. (1977). Campylobacter enteritis: a "new" disease. Br Med J 2, 9-11.

Skirrow, M. B. \& Blaser, M. J. (1992). Clinical and epidemiologic considerations. In Campylobacter jejuni: Current Status and Future Trends, pp. 3-8. Edited by I. Nachamkin, M. J. Blaser \& L. S. Tompkins. Washington, DC: American Society for Microbiology.

Tauxe, R. V. (1992). Epidemiology of Campylobacter jejuni infections in the United States and other industrialized nations. In Campylobacter jejuni: Current Status and Future Trends, pp. 9-19. Edited by I. Nachamkin, M. J. Blaser \& L. S. Tompkins. Washington, DC: American Society for Microbiology.

Taylor, D. N. (1992). Campylobacter infections in developing countries. In Campylobacter jejuni: Current Status and Future Trends, pp. 20-30. Edited by I. Nachamkin, M. J. Blaser \& L. S. Tompkins. Washington, DC: American Society for Microbiology.

Toker, A. S. \& Macnab, R. M. (1997). Distinct regions of bacterial flagellar switch protein FliM interact with FliG, FliN and CheY. J Mol Biol 273, 623-634.

Tomb, J. F., White, O., Kerlavage, A. R. \& 39 other authors (1997). The complete genome sequence of the gastric pathogen Helicobacter pylori. Nature 388, 539-547.

Wang, Y. \& Taylor, D. E. (1990). Chloramphenicol resistance in Campylobacter coli: nucleotide sequence, expression, and cloning vector construction. Gene 94, 23-28.

Wassenaar, T. M., Bleumink-Pluym, N. M. C. \& van der Zeijst, B. A. M. (1991). Inactivation of Campylobacter jejuni flagellin genes by homologous recombination demonstrates that $f l a A$ but not $f l a B$ is required for invasion. EMBO $J$ 10, 2055-2061.

Wassenaar, T. M., Fry, B. N. \& van der Zeijst, B. A. M. (1993). Genetic manipulation of Campylobacter: evaluation of natural transformation and electro-transformation. Gene 132, 131-135.

Yao, R., Burr, D. H., Doig, P., Trust, T. J., Niu, H. \& Guerry, P. (1994). Isolation of motile and non-motile insertional mutants of Campylobacter jejuni: the role of motility in adherence and invasion of eukaryotic cells. Mol Microbiol 14, 883-893.

Received 6 January 1999; revised 6 April 1999; accepted 13 April 1999. 